Marquette University

e-Publications@Marquette

Biomedical Engineering Faculty Research and

Publications

Engineering, College of

$1-1-2002$

\title{
Reengineering Biomedical Engineering Curricula: A New Product Development Approach
}

Robert A. Scheidt

Marquette University, robert.scheidt@marquette.edu

L. Waples

Marquette University

Kristina M. Ropella

Marquette University, kristina.ropella@marquette.edu

Accepted version. Published as part of the proceedings of the conference, Second Joint EMBS/BMES Conference, 2002: 2628-2629. DOI. (C) 2002 Institute of Electrical and Electronics Engineers (IEEE). Used with permission. 


\title{
Reengineering Biomedical Engineering Curricula: A New Product Development Approach
}

\author{
R.A. Scheidt \\ Department of Biomedical Engineering, Marquette University, Milwaukee, WI \\ L. Waples \\ Department of Biomedical Engineering, Marquette University, Milwaukee, WI \\ K.M. Ropella \\ Department of Biomedical Engineering, Marquette University, Milwaukee, WI
}

\begin{abstract}
Product development engineers in medical industries have created design control procedures to ensure high quality designs that are as error-free as possible. The reason is simple; companies must adhere to certain engineering and manufacturing "best practices" in order to obtain certification of their devices for sale in the US and abroad. We describe here an ongoing effort to apply these industrial "best practices" to the design and implementation of a novel sequence of undergraduate biomedical computing courses within the Department of Biomedical Engineering at Marquette University (Milwaukee, Wisconsin). We have tightly integrated our industrial advisory board into this design and development effort. The board has contributed to significantly to the orderly generation of curricular requirements, the development of course implementation designs and the evaluation of these designs per requirements.
\end{abstract}


NOT THE PUBLISHED VERSION; this is the author's final, peer-reviewed manuscript. The published version may be accessed by following the link in the citation at the bottom of the page.

\section{SECTION I.}

\section{Introduction}

We are implementing a new curriculum in the Department of Biomedical Engineering Biocomputer Engineering, which prepares students for software systems engineering positions in the medical industry. This new curriculum 00-dresses explicit needs identified by industry. to develop engineers with competency in current hardware and software technologies, physiological concepts, as well as in design processes and methodologies that have proven successful in launching new applications in the FDA regulated medical industry. Because we constantly strive to develop curricula of the highest quality, we endeavored to apply industrial quality control strategies to our curriculum development process. These strategies have included the regular use of requirements analyses, design reviews, assessment per requirements and the use of a simple issues tracking and resolution system. Although we are only half way through implementation, this strategy has resulted in very favorable responses from both industrial partners and students.

\section{SECTION II.}

\section{Methodology}

A standard spiral design approach ${ }^{1}$ is being used to develop the new Biocomputer Engineering curriculum in the Department of Biomedical Engineering at Marquette University. We have modified the standard approach slightly to fit our curriculum development needs. The strategy we use includes the following five stages:

\section{1) Requirements Analysis}

Initial discussions with our industrial advisory partners suggested that our graduating Biomedical Engineering students were lacking in skills necessary for the development of computer-based biomedical applications. Four broad areas of knowledge were targeted for specific attention: technology, physiology, product development processes as well as specific analysis and design methodologies. We solicited feedback from our industrial' partners as to what topics and subject matter were of greatest importance for their individual business units withn each of these four knowledge areas. This feedback was compiled into a set of requirements that is used in guiding the development of our Biocomputing curriculum.

Proceedings of the Second Joint EMBS/BMES Conference, 2002, Vol 3, (2002): 2628-2629. DOI. This article is @ Institute of Electrical and Electronics Engineers (IEEE) and permission has been granted for this version to appear in e-Publications@Marquette. Institute of Electrical and Electronics Engineers (IEEE) does not grant permission for this article to be further copied/distributed or hosted elsewhere without the express permission from Institute of Electrical and Electronics Engineers (IEEE). 
NOT THE PUBLISHED VERSION; this is the author's final, peer-reviewed manuscript. The published version may be accessed by following the link in the citation at the bottom of the page.

\section{2) Curricular Design and Review}

Over the past four years, meetings were convened with members of our industrial advisory board to review proposed curricular requirements and implementation plans as well as to assess the results of implementation per our stated requirements. The board members that participated in these review sessions were senior software and hardware design managers from a variety of large and small medical device and electronics manufacturers including: GE Medical Systems, Abbott Laboratories, Baxter Healthcare, Datex-Ohmeda, Medical Research Laboratories, Medtronic, Kimberly-Clark and others. The timing of these reviews was carefully chosen to provide maximal input into the development of both the overall biocomputing curriculum as well as individual courses within that curriculum. These design review sessions addressed both broad concerns such as the technical content to be covered over the four year program as well as specific implementation issues such as how to best integrate hands-on learning experiences into an embedded systems design course without a formal laboratory component The outcome of each session was a document summarizing consensus solutions to specific issues as well as points of contention between business groups with differing viewpoints.

\section{3) Implementation}

We augmented our own internal curricular development activities by utilizing industrial consultants to assist in the detailed design of specific coursework. These consultants (members of our industrial advisory board) helped map curricular requirements onto specific classroom activities including both lecture content as well as laboratory exercises. We then analyzed the implementation plan for content in our four areas of concern (technical, physiological, process and methodology) in order to determine the content we most wanted students to learn. This analysis was used to select lecture '(.+)' environment was prepared and equipment was procured to support the laboratory experiences as designed.

\section{4) Assessment}

We are using several mechanisms to assess the quality of our first, new biocomputer engineering courses and to determine whether we addressed our stated requirements. Student deliverables (reports and exams) were inspected for competency in the four target subject areas: technology, physiology, process and methodology. Course content was compared against the original educational content grid and specific material not addressed

Proceedings of the Second Joint EMBS/BMES Conference, 2002, Vol 3, (2002): 2628-2629. DOI. This article is @ Institute of Electrical and Electronics Engineers (IEEE) and permission has been granted for this version to appear in e-Publications@Marquette. Institute of Electrical and Electronics Engineers (IEEE) does not grant permission for this article to be further copied/distributed or hosted elsewhere without the express permission from Institute of Electrical and Electronics Engineers (IEEE). 
NOT THE PUBLISHED VERSION; this is the author's final, peer-reviewed manuscript. The published version may be accessed by following the link in the citation at the bottom of the page.

was identified. Marquette University's student evaluation forms were analyzed and industrial advisory board feedback was solicited

\section{5) Lessons Learned and Requirements Adjustment}

We analyzed our course development assessment outcomes in order to identify areas of potential pedagogical improvement as well as to identify any curricular requirements that need adjustment or redefinition. This last step in the development process is imperative to the evolution of products of ever-increasing quality (regardless of whether that product is a medical device or a novel undergraduate curriculum).

\section{SECTION III.}

\section{Results}

To date, we have implemented and executed one new courses in the biocomputing curriculum according to the plan outlined above: BIEN1 12 - Embedded Biomedical Instrumentation, a 3-credit Junior-level course focusing on medical electronics and embedded microcontroller technology. Two new senior-level laboratory courses are currently in active development using this approach. The first of the two (BIEN193) will be taught in the Fall of 2002 and will focus on physiological simulation, monitoring and control while the second senior course (BIEN194) will be taught in the Spring 2003 and will focus and medcal informatics, data visualization and mning.

Example outcomes and deliverables for each development stage is presented here using BIEN 112 as a case study:

1. The requirements analysis activities yielded liss of educational objectives that expanded each of the four primary curricular concentrations into lists of important concepts students must grasp and skills they should have on matriculation These lists were compiled into a master list that serves as a requirements definition document for use in guiding the continuing development of our undergraduate biocomputing courses. For example, of the 19 itemized curricular objectives, the Junior BIEN112 course addresses 12, while the pt senior course addresses 14 and the $2^{\text {nd }}$ senior course addresses 8 . This may not be as unbalanced as might first seem because the initial courses introduce many simpler, fundamental concepts while the $2^{\text {nd }}$ senior course takes time to develop more challenging material.

2. A preliminary course plan was developed for the junior undergraduate biocomputing course early in the summer $0 £ 2001$. A design review was held at a GE 
Medical Systems facility in June 2001 to review the proposed implementation of the Junior biomedical instrumentation course, BIENl12. Approximately 15 hardware and software engineering managers and designers participated in the e-view. Specific feedback was solicited on how to best integrate hands-on learning experiences into an embedded systems design course scheduled without formal laboratory sessions. A solution was suggested whereby the 16-week course was divided into 8 topical modules comprised of about four, 50-minute lecture sessions and two, 50-minute laboratory sessions within each 2 week period. The course content was assessed to be satisfactory, although aggressive in scope.

3. BIENl12 was implemented in Fall 2002 with 8 students. During the term students asked-to have additional emphasis on assembly language programming for the Motorola 68HC12. Additional lecture content was added per this request. Later emphasis on design methodology was dropped to accommodate the increased focus on technology. For the final exam, students generated design documentation and pseudocode for a wearable, noninvasive blood pressure monitoring device. This required students to integrate material presented throughout the entire term, including the generation of UML use cases, requirements definition documents, hazard/risk assessment, detailed design, software pseudocode, validation/verification plans (including a sample test case) as well as an assessment of resources and time needed for the generation of an initial prototype.

4. The original course requirements document was compared against the course as implemented to assess how well the course covered the required material. Of the course content scheduled, 3 topic areas were not implemented in order to keep student workload at a reasonable level. Even so, students found the course workload to be heavy and suggested that the course would be much improved if extended laboratory time was integrated into the schedule The requirement coverage analysis, student comments and examples of student deliverables were presented to an industrial advisory panel which found the course implementation to meet or exceed expectations. The panel opined that all of the material covered in the current implementation is important and desirable. They also agreed that cutting material to bring the workload in line with undergraduate expectations was not advised, but that adding a 3-hour laboratory section was a reasonable and necessary alteration.

5. In light of student commentary and upon the recommendation of the industrial advisory panel, a new lab section was added for the Fall 2002 implementation of BIENI12. No other significant changes are planned in the curriculum of BIEN 112. 


\section{SECTION IV.}

\section{Discussion and Conclusion}

We propose that the process outlined above and exemplified in the implementation of BIEN112 can be used to maximize the relevance of engineering curriculum as well as to ensure that the students get the highest quality education possible. The development of quality engineering curriculum can be compared to the development of any other quality product; consequently, the application of industrial 'best practices" for quality control may be expected to yield benefits in academia just as they do in industry.

\section{ACKNOWLEDGEMENT}

This work was funded by a Special Opportunity Award from The Whitaker Foundation.

\section{References}

${ }^{1}$ A.P. Sage, Systems Engineering, Wiley and Sons, pp. 52-57, 1992. 